\title{
PLANT ECOLOGY
}

\section{Invasive species like it hot \\ Ecol. Lett. http://doi.org/gf3jfj (2019).}

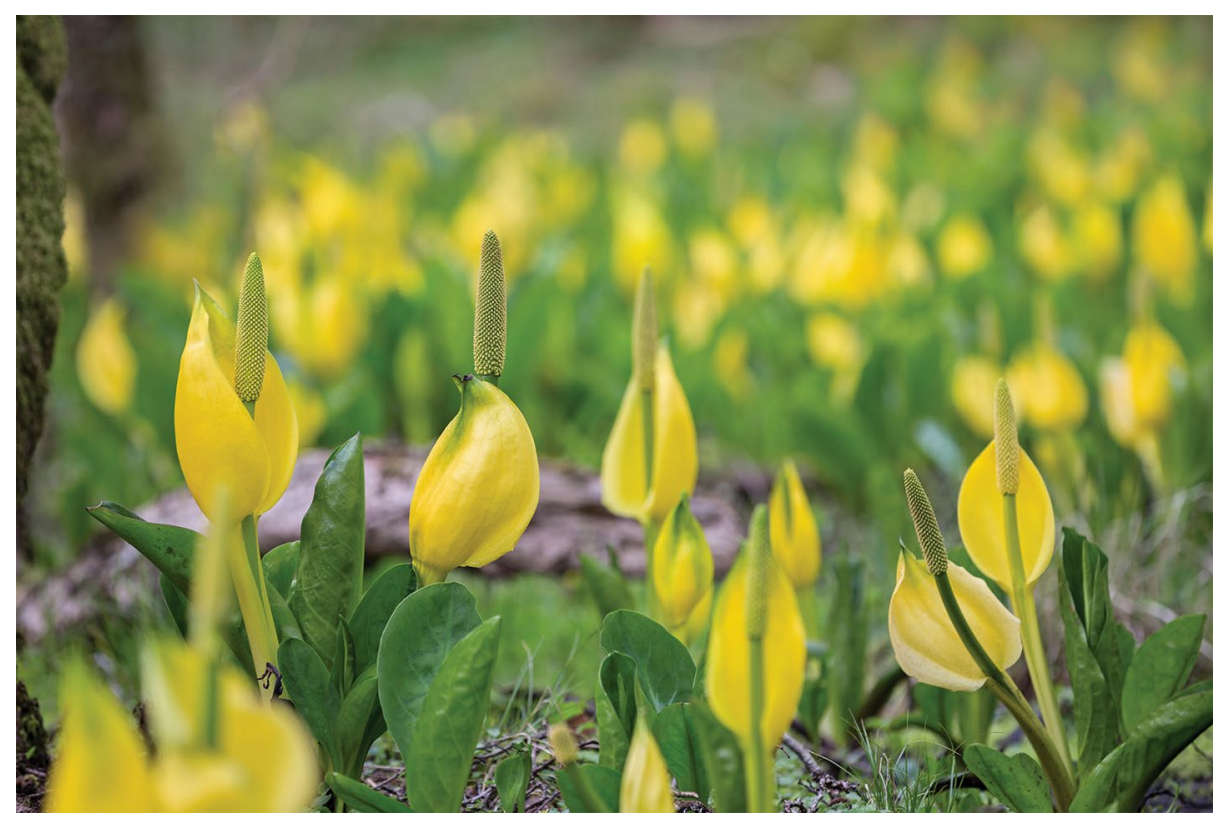

Credit: David Cheshire / Alamy Stock Photo

Non-native species seem to adapt better to climate variability than native ones, so analysing how global warming might affect plant invasive potential is essential to evaluate possible forthcoming ecological and economic impacts. Based on an experiment performed within the warming array of the Kellog Biological Station in Michigan, USA, Meredith Zettlemoyer and colleagues from Michigan State University have analysed the effects of $\mathrm{a}+3^{\circ} \mathrm{C}$ warming (as predicted for this region by the end of this century) on the phenology of 42 flowering plant species: native, non-native, invasive and non-invasive.

The researchers found that warming accelerated flowering and fruiting of nonnative species and enhanced synchrony among them, whereas it did not affect native species. Furthermore, they observed that early flowering was associated with an increased spatial spread of non-native species. They also found that invasive species with a longer history in the area better adapted their flowering and fruiting times to environmental change than those more recently introduced. However, this did not happen for non-native species that were also non-invasive.

In the face of a warming world, nonnative plant species, and particularly those presenting an invasive potential, may become even more competitive than natives, having earlier access to resources and pollinators. These results have important implications not only for understanding historical plant community shifts associated with past warming events, but also for predicting future ecosystem changes and designing successful strategies to manage the consequences of climate change.

\section{Abel Barral}

Published online: 1 July 2019

https://doi.org/10.1038/s41477-019-0483-z 